\title{
Host Defenses in Experimental Rickettsialpox: Genetics of Natural Resistance to Infection
}

\author{
GEORGE W. ANDERSON, JR.,' AND JOSEPH V. OSTERMAN ${ }^{2 *}$ \\ Virology Division, United States Army Medical Research Institute of Infectious Diseases, Frederick, \\ Maryland 21701, ${ }^{1}$ and Department of Rickettsial Diseases, Walter Reed Army Institute of Research, \\ Washington, D.C. $20012^{2}$
}

\begin{abstract}
The genetic basis for natural resistance to lethal infection with Rickettsia akari was studied in over 25 inbred strains, inbred hybrids, and outbred stocks of mice. Inbred mice infected intraperitoneally with the Kaplan strain of $R$. akari demonstrated three levels of response: susceptible $(\mathrm{C} 3 \mathrm{H} / \mathrm{HeJ})$, intermediate $(\mathrm{A} / \mathrm{HeJ}$, $\mathrm{A} / \mathrm{J}, \mathrm{A} / \mathrm{WySn}, \mathrm{BALB} / \mathrm{cDub}, \mathrm{BALB} / \mathrm{cJ}$, and $\mathrm{SJL} / \mathrm{J})$, and resistant (AKR/J, AL/ $\mathrm{N}, \mathrm{BALB} / \mathrm{cAnN}, \mathrm{BALB} / \mathrm{cNCr} 1 \mathrm{BR}, \mathrm{C} 3 \mathrm{H} / \mathrm{HeN}, \mathrm{C} 57 \mathrm{BL} / 6 \mathrm{~J}, \mathrm{C} 57 \mathrm{~L} / \mathrm{J}, \mathrm{CBA} / \mathrm{J}$, $\mathrm{DBA} / 2 \mathrm{~J}$, and SWR/J). No correlation was evident between the six $H-2$ haplotypes tested and susceptibility to Kaplan infection. Four outbred mouse stocks, Dub:(ICR), Wrc:(ICR), Caw:(CF1), and Mai:(S) were all resistant. The $F_{1}$ inbred hybrids of resistant $\times$ resistant $\left(A K D 2 F_{1} / J\right)$, resistant $\times$ intermediate $\left(\mathrm{CB} 6 \mathrm{~F}_{1} / \mathrm{J}\right)$, intermediate $\times$ intermediate $\left(\mathrm{CAF}_{1} / \mathrm{J}\right)$, and resistant $\times$ susceptible $\left(\mathrm{C} 3 \mathrm{D} 2 \mathrm{~F}_{1} / \mathrm{J}\right)$ parents were all resistant. The $\mathrm{F}_{2}$ and parental backcross generations of $\mathrm{C} 3 \mathrm{H} /$ $\mathrm{HeJ}$ and DBA/2J hybrids yielded ratios of resistant to susceptible mice that suggested resistance was under multigeneic control. Susceptible mice $(\mathrm{C} 3 \mathrm{H} / \mathrm{HeJ})$ were capable of mounting an immune response, since prior infection with the avirulent Hartford strain of $R$. akari rendered them resistant to subsequent lethal challenge with the Kaplan strain.
\end{abstract}

The use of inbred mice has facilitated the study of genetic factors in resistance or susceptibility of mice to viral $(3,12,13)$, bacterial $(2$, $14,15)$, and protozoan $(1,21)$ infections. Recently, this approach was employed to examine the influence of host genetic background on susceptibility of mice to rickettsial infection. A survey of outbred mouse stocks and inbred mouse strains showed different patterns of susceptibility to Rickettsia tsutsugamushi, depending on the strain of scrub typhus rickettsiae employed for challenge (7). Study of $F_{1}, F_{2}$, and parental backcross generations of BALB/c and C3H hybrids challenged with $R$. tsutsugamushi strain Gilliam indicated that resistance was dominant and controlled by a single gene or a closely linked cluster of autosomal genes not associated with the $H$-2 locus.

At present, there is very limited information available concerning the influence of genetic factors on the susceptibility of mice to other species of rickettsiae. Rickettsia akari, the etiological agent of rickettsialpox, was found to be lethal for some outbred mouse stocks during initial attempts at isolation and propagation of the agent $(8,9)$. A limited survey of inbred mouse strains and assessment of one outbred stock indicated that the BALB/cJ strain and the Mai: (S) stock were susceptible to a very large dose of the Kaplan strain of $R$. akari (17). More recently, another brief study of several strains of mice challenged with the M3 strain of $R$. akari indicated that the DBA mouse strain differed from others in its heightened resistance to lethal rickettsial infection (11). The resistance of DBA strain mice to $R$. akari was in direct contrast to results of previous studies with $R$. tsutsugamushi (7), which indicated that the DBA strain was exquisitely sensitive to lethal infection. The different response of this inbred strain to each rickettsial challenge suggested that a pattern of resistance quite different from that seen with scrub typhus agents could emerge from the interaction of $R$. akari with inbred strains of mice.

Rickettsial agents traditionally have been considered simply as mouse virulent or avirulent, with little consideration given to the influence of the genetic background of the host. We believed that a continuation of our genetic studies, employing a member of the spotted fever antigenic group, would provide a broader perspective of rickettsiae-host interactions.

In this report, we (i) present a survey of outbred mouse stocks and inbred mouse strains for susceptibility to $R$. akari, (ii) assess the resistance of $F_{1}$ hybrids derived from inbred parents of both similar and different rickettsial susceptibilities, and (iii) evaluate the resistance 
of $F_{2}$ and parental backcross generations of a selected inbred hybrid.

\section{MATERIALS AND METHODS}

Animals. Seventeen inbred mouse strains were used. A/HeJ, A/J, A/WySn, AKR/J, BALB/cJ, C3H/ HeJ, C57BL/6J, C57L/J, CBA/J, DBA/2J, SJL/J, and SWR/J were purchased from the Jackson Memorial Laboratory, Bar Harbor, Maine. BALB/cDub were purchased from Flow Laboratories, Dublin, Va. BALB/cNCr1BR were purchased from Charles River Breeding Laboratories, Inc., Wilmington, Mass. AL/ $\mathrm{N}, \mathrm{BALB} / \mathrm{cAnN}$, and $\mathrm{C} 3 \mathrm{H} / \mathrm{HeN}$ mice were generously provided by the Division of Research Services, National Institutes of Health, Bethesda, Md.

Several inbred hybrid crosses were studied. $\mathrm{AKD}_{2} \mathrm{~F}_{1} / \mathrm{J} \quad(\mathrm{AKR} / \mathrm{J} \times \mathrm{DBA} / 2 \mathrm{~J} \mathrm{male}), \mathrm{CAF}_{1} / \mathrm{J}$ $\left(\mathrm{BALB} / \mathrm{cJ} \times \mathrm{A} / \mathrm{J}\right.$ male), $\mathrm{CB} \mathrm{F}_{1} / \mathrm{J}$ (BALB/cJ $\times$ C57BL/6J male), and C3D2F $1 / \mathrm{J}(\mathrm{C} 3 \mathrm{H} / \mathrm{HeJ} \times \mathrm{DBA} /$ $2 \mathrm{~J}$ male) were purchased from the Jackson Memorial Laboratory. The $\mathrm{F}_{2}\left(\mathrm{C} 3 \mathrm{D} 2 \mathrm{~F}_{1} / \mathrm{J} \times \mathrm{C}_{3} \mathrm{D} 2 \mathrm{~F}_{1} / \mathrm{J}\right)$ mice and parental backcross mice (C3D2F $1 \times \mathrm{C} 3 \mathrm{H} / \mathrm{HeJ}$ male) and (C3D2F $1 \times$ DBA/2J male) were bred in our laboratory with breeding stock obtained from the Jackson Memorial Laboratory.

Four outbred mouse stocks were studied. Wrc:(ICR) were obtained from the Division of Animal Resources, Walter Reed Army Institute of Research, Washington, D.C. Caw:CF1 (albino) were purchased from Charles River Breeding Laboratories, Inc., Wilmington, Mass. Dub:(ICR) were purchased from Flow Laboratories, Dublin, Va. Mai:(S) were purchased from Microbiological Associates, Bethesda, Md.

All mice were tested at 6 to 8 weeks of age and were males unless otherwise noted.

Rickettsiae. The Kaplan (egg passage 21) and Hartford (egg passage 15) strains of $R$. akari were plaqued (20), and single-plaque isolates were propagated in embryonated chicken eggs. This plaque isolation was repeated during the next two consecutive passages of rickettsiae, resulting in a triple plaquepurification of isolates. These strains of $R$. akari, as well as the Breinl strain of $R$. prowazekii (egg passage 127) were propagated in embryonated chicken eggs and stored in small portions by standard methods (18). The $R$. akari inocula used for mouse challenges were prepared from the second egg passage after completion of plaque purification.

Evaluation of susceptibility. The $50 \%$ mouse lethal dose $\left(M^{\prime} D_{50}\right)$ was determined by infecting groups of five mice intraperitoneally with $0.2 \mathrm{ml}$ each of 10 fold dilutions of a standard suspension of $R$. akari. In one experiment employing $\mathrm{C} 3 \mathrm{H} / \mathrm{HeJ}$ mice, the $\mathrm{MLD}_{50}$ was determined after subcutaneous inoculation of rickettsiae. At the time of each experiment, the number of viable rickettsiae in the standard suspension was also determined by plaque assay in chicken embryo fibroblast cells (20). After observation of infected mice for 28 days, the $\log _{10} M L D_{50}$ and standard deviations were calculated by the method of Spearman and Karber (5) and expressed in plaque-forming units (PFU). The response patterns of mice were defined as susceptible, intermediate, or resistant. Susceptible mice were characterized by a $\log _{10} \mathrm{MLD}_{50}<1$; intermediate mice were characterized by a $\log _{10} M L D_{50}>1$ but $₹ 3$; and resistant mice evidenced a $\log _{10} \mathrm{MLD}_{50}>3$.

\section{RESULTS}

Survey of mice for response to $R$. akari Kaplan. The $\mathrm{C} 3 \mathrm{H} / \mathrm{HeJ}$ strain was clearly the most susceptible, but there was a range of $\log _{10}$ $M^{M L D}{ }_{50}$ s from 0 to 5.1 (Table 1). Examination of several sublines from well-documented strains failed to show a consistent pattern. The three sublines of the A strain showed a similar intermediate level of resistance, but the four sublines of the BALB/c strain appeared to fall into two groups; the $\mathrm{C} 3 \mathrm{H}$ sublines examined represented the extremes of the response pattern. In addition, no correlation was apparent between susceptibility to infection and known $H-2$ haplotypes (19).

Four outbred stocks of mice examined (Table 2) were all resistant to challenge with $R$. akari.

\begin{tabular}{|c|c|c|c|}
\hline Inbred strain & $\begin{array}{c}\log _{10} \\
\mathrm{MLD}_{50} \\
(\mathrm{PFU} \pm \\
\mathrm{SD})^{a}\end{array}$ & $\begin{array}{c}H-2 \\
\text { haplo- } \\
\text { type }\end{array}$ & $\begin{array}{c}\text { Response pat- } \\
\text { tern }\end{array}$ \\
\hline A/HeJ & $1.7 \pm 0.2$ & $a$ & Intermediate \\
\hline $\mathbf{A} / \mathbf{J}$ & $2.2 \pm 0.2$ & $a$ & Intermediate \\
\hline A/WySn & $1.9 \pm 0.3$ & $a$ & Intermediate \\
\hline AKR/J & $3.8 \pm 0.3$ & $\boldsymbol{k}$ & Resistant \\
\hline $\mathbf{A L} / \mathbf{N}$ & $5.0 \pm 0.3$ & $a$ & Resistant \\
\hline BALB/cAnN & $4.3 \pm 0.2$ & $d$ & Resistant \\
\hline BALB/cDub & $3.0 \pm 0.3$ & $d$ & Intermediate \\
\hline BALB/cJ & $2.5 \pm 0.2$ & $d$ & Intermediate \\
\hline BALB/cNCr1BR & $4.2 \pm 0.2$ & $d$ & Resistant \\
\hline C3H/HeJ & $0 \pm 0.1$ & $\boldsymbol{k}$ & Susceptible \\
\hline $\mathrm{C} 3 \mathrm{H} / \mathrm{HeN}$ & $5.1 \pm 0.2$ & $\boldsymbol{k}$ & Resistant \\
\hline C57BL/6J & $3.2 \pm 0.2$ & $b$ & Resistant \\
\hline $\begin{array}{r}\text { C57BL/6J } \\
\text { (female) }\end{array}$ & $3.7 \pm 0.5$ & $b$ & Resistant \\
\hline C57L/J & $4.2 \pm 0.2$ & $b$ & Resistant \\
\hline CBA/J & $4.6 \pm 0.2$ & $\boldsymbol{k}$ & Resistant \\
\hline DBA/2J & $4.2 \pm 0.1$ & $d$ & Resistant \\
\hline SJL/J & $3.0 \pm 0.3$ & $s$ & Intermediate \\
\hline SWR/J & $4.1 \pm 0.2$ & $q$ & Resistant \\
\hline
\end{tabular}

${ }^{a} \mathrm{SD}$, Standard deviation.

TABLE 2. Response of outbred mouse stocks to $R$. akari Kaplan

\begin{tabular}{lcl}
\hline \multicolumn{1}{c}{ Outbred stock } & $\begin{array}{c}\log _{10} \mathrm{MLD}_{50} \\
(\mathrm{PFU} \pm \mathrm{SD})^{a}\end{array}$ & Response pattern \\
\hline $\begin{array}{l}\text { Swiss } \\
\text { Mai:(s) }\end{array}$ & $3.8 \pm 0.2$ & Resistant \\
$\begin{array}{l}\text { Albino } \\
\text { Caw:CF }\end{array}$ & $4.2 \pm 0.2$ & Resistant \\
$\begin{array}{l}\text { ICR } \\
\text { Dub:(ICR) } \\
\text { Wrc:(ICR) }\end{array}$ & $4.7 \pm 0.2$ & Resistant \\
\hline
\end{tabular}

${ }^{a} \mathrm{SD}$, Standard deviation. 
One outbred stock (ICR) obtained from two different suppliers, but with a similar genetic origin, showed a uniform response to challenge.

Response of $F_{1}$ inbred hybrid mice to $\mathrm{Ka}$ plan strain. Four types of parental crosses were examined; resistant $X$ resistant $\left(\mathrm{AKD} \mathrm{F}_{1} / \mathrm{J}\right)$; intermediate $x$ intermediate $\left(\mathrm{CAF}_{1} / \mathrm{J}\right)$; resistant $X$ intermediate $\left(\mathrm{CB} \mathrm{F}_{1} / \mathrm{J}\right)$; and resistant $X$ susceptible $\left(\mathrm{C} 3 \mathrm{D} 2 \mathrm{~F}_{1} / \mathrm{J}\right)$. Since $\mathrm{C} 3 \mathrm{H} / \mathrm{HeJ}$ was the only susceptible strain identified, a susceptible $X$ susceptible cross was not possible. As shown in Table 3, all progeny responded as resistant mice regardless of the response pattern of the parental strains. Inoculation of male and female offspring indicated resistance was not sex linked.

Response to Kaplan strain infection of $F_{2}$ and parental backcross generations of C3H/HeJ and DBA/2J mice. To examine the genetics of resistance to Kaplan strain infection, large groups of $F_{2}\left(C 3 D 2 F_{1} / J \times C 3 D 2 F_{1} / J\right)$ and parental backcross $\left(F_{1} \times\right.$ male parent) generations resulting from $\mathrm{C} 3 \mathrm{H} / \mathrm{HeJ}$ and $\mathrm{DBA} / 2 \mathrm{~J}$ crosses were inoculated intraperitoneally with approximately 100 PFU of $R$. akari Kaplan.

Progeny of the backcross of $F_{1}$ by a resistant parent were all resistant (Table 4), again suggesting that resistance was a dominant trait. The backcross of $F_{1}$ by a susceptible parent yielded a ratio of six resistant to one susceptible, and the $F_{1} \times F_{1}$ cross $\left(F_{2}\right)$ produced a ratio of 46 resistant progeny to one susceptible. The predicted re-

TABLE 3. Response of $F_{1}$ inbred hybrid mice to Kaplan infection

\begin{tabular}{|c|c|c|c|}
\hline$F_{1}$ hybrid & Sex & $\begin{array}{c}\log _{10} \\
\mathrm{MLD}_{50} \\
(\mathrm{PFU} \pm \\
\mathrm{SD})^{a}\end{array}$ & $\begin{array}{c}\text { Response } \\
\text { pattern }\end{array}$ \\
\hline $\begin{array}{l}\mathrm{AKD} 2 F_{1} / J(A K R / J \times D B A / \\
2 \mathbf{J}) \\
\mathrm{CAF}_{1} / \mathbf{J}(\mathbf{B A L B} / \mathbf{c} \mathbf{J} \times \mathbf{A} / \mathbf{J})\end{array}$ & $\begin{array}{l}\mathbf{M} \\
\mathbf{F} \\
\mathbf{M} \\
\mathbf{F}\end{array}$ & $\begin{array}{l}4.6 \pm 0.2 \\
5.1 \pm 0.2 \\
3.2 \pm 0.2 \\
3.6 \pm 0.5\end{array}$ & $\begin{array}{l}\text { Resistant } \\
\text { Resistant } \\
\text { Resistant } \\
\text { Resistant }\end{array}$ \\
\hline 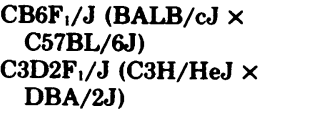 & $\begin{array}{l}\mathbf{M} \\
\mathbf{F} \\
\mathbf{M} \\
\mathbf{F}\end{array}$ & $\begin{array}{l}4.6 \pm 0.1 \\
4.4 \pm 0.2 \\
4.1 \pm 0.2 \\
4.9 \pm 0.2\end{array}$ & $\begin{array}{l}\text { Resistant } \\
\text { Resistant } \\
\text { Resistant } \\
\text { Resistant }\end{array}$ \\
\hline
\end{tabular}

${ }^{a}$ SD, Standard deviation.

TABLE 4. Response of $F_{2}$ and parental backcross generations of $\mathrm{C} 3 \mathrm{H} / \mathrm{HeJ}$ and $\mathrm{DBA} / 2 \mathrm{~J}$ mice to Kaplan infection

\begin{tabular}{|c|c|}
\hline Hybrid & $\begin{array}{l}\text { No. survivors/no. of of } \\
\text { mice challenged }^{a}\end{array}$ \\
\hline $\begin{array}{l}\text { Parental backcross } \\
\text { DBA } / 2 \mathrm{~J} \times \mathrm{C} 3 \mathrm{D} 2 \mathrm{~F}_{1} / \mathrm{J} \\
\text { C3H } / \mathrm{HeJ} \times \mathrm{C} 3 \mathrm{D} 2 \mathrm{~F}_{1} / \mathrm{J}\end{array}$ & $\begin{array}{l}174 / 174 \\
197 / 229\end{array}$ \\
\hline $\begin{array}{l}\mathrm{F}_{2} \\
\quad \mathrm{C} 3 \mathrm{D} 2 \mathrm{~F}_{1} / \mathrm{J} \times \mathrm{C} 3 \mathrm{D} 2 \mathrm{~F}_{1} / \mathrm{J}\end{array}$ & $92 / 94$ \\
\hline
\end{tabular}

${ }^{a}$ Mice were challenged with 100 PFU of Kaplan sistance:susceptibility ratios, if resistance is governed by a single autosomal dominant gene, are 1:1 for the progeny of $F_{1} \times$ susceptible parent and 3:1 for the progeny of $F_{1} \times F_{1}$. The magnitude of the deviation from these ratios suggested that resistance was under multigeneic control.

Replication of Kaplan strain in primary mouse embryo cell cultures. The vast difference in susceptibility of $\mathrm{C} 3 \mathrm{H} / \mathrm{HeJ}$ and resistant mouse strains to infection with $R$. akari Kaplan could result from a physiological inability of cells from the resistant mouse strains to support the replication of rickettsiae. To determine whether Kaplan strain organisms could replicate in cells from a resistant animal, embryo cell cultures were prepared from C3D2F 1 hybrid mice. Similar monolayer cultures of chicken embryo fibroblast cells were also prepared, and duplicate plaque assays were performed with a single suspension of the Kaplan strain. There was no difference in the plaque titer observed with chicken embryo cells, known to support the replication of $R$. akari (20), and with C3D2F $\mathrm{F}_{1}$ mouse embryo cells.

Immunization of C3H/HeJ mice with $R$. akari Hartford. Differences in survival of mice after experimental rickettsialpox infection could be related to host immunological deficiences that preclude an effective immune response to the rickettsiae. To determine whether $\mathrm{C} 3 \mathrm{H} / \mathrm{HeJ}$ mice could mount a protective immune response, we attempted to immunize animals by subcutaneous inoculation with viable $R$. akari Kaplan, since this route of administration had produced a nonlethal immunizing infection in previous studies with $R$. tsutsugamushi (7). We found that either subcutaneous or intraperitoneal inoculation of $\mathrm{C} 3 \mathrm{H} / \mathrm{HeJ}$ mice with approximately 1 PFU of $R$. akari Kaplan resulted in a lethal infection. The immunocompetence of these mice was demonstrated by intraperitoneal inoculation of the avirulent Hartford strain of $R$. akari followed by challenge with the virulent Kaplan strain. Immunization of $\mathrm{C} 3 \mathrm{H} / \mathrm{HeJ}$ mice was accomplished using either $10^{4}$ or $10^{6} \mathrm{PFU}$ of the Hartford strain (Table 5). As previously reported (4), the response was rickettsial species specific, since inoculation of mice with $R$. prowazekii had no effect on their subsequent susceptibility to challenge with $R$. akari Kaplan.

\section{DISCUSSION}

The results of our studies clearly indicated a broad range in the resistance of mice to lethal infection with $R$. akari. Among the inbred strains, some resistant mice survived a challenge approximately $10^{5}$ times greater than a dose capable of killing the highly susceptible $\mathrm{C} 3 \mathrm{H}$ / 
TABLE 5. Effect of prior immunization on the response of $\mathrm{C} 3 \mathrm{H} / \mathrm{HeJ}$ mice to infection with $R$. akari Kaplan

\begin{tabular}{lcc}
\hline Immunogen & $\begin{array}{c}\text { Dose }^{a} \\
\text { (PFU) }\end{array}$ & $\begin{array}{c}\text { No. of survivors/ } \\
\text { no. immunized } \\
\text { mice challenged }\end{array}$ \\
\hline R. akari Hartford & $10^{6}$ & $10 / 10$ \\
R. prowazekii Breinl & $10^{4}$ & $10 / 10$ \\
None & $10^{6}$ & $0 / 10$ \\
& $10^{4}$ & $0 / 10$ \\
\hline
\end{tabular}

${ }^{a}$ Mice were challenged with 1,000 PFU of the Kaplan strain 28 days after administration of immunogen.

HeJ strain. Outbred stocks were all considered resistant by our criteria, but resistance could be overcome by very large inocula of rickettsiae, as previously reported for the Mai:(S) stock (17).

The response pattern of individual strains of inbred mice showed little correlation with original breeding stock. The $\mathrm{C} 3 \mathrm{H} / \mathrm{HeJ}$ strain was the most susceptible tested in this study, whereas the $\mathrm{C} 3 \mathrm{H} / \mathrm{HeN}$ strain was the most resistant. The BALB/cAnN and BALB/cNCr1BR strains were both resistant, whereas BALB/cDub and $\mathrm{BALB} / \mathrm{cJ}$ were classified in the intermediate category. Investigators utilizing a strain of C57BL/6 mice, obtained within the Soviet Union, have reported these animals to be highly susceptible to infection with the M3 strain of $R$. akari (11). This strain of mice and strain of rickettsiae have also been employed for studies on the pathogenesis of rickettsialpox infection in laboratory animals (10). Our results indicated that C57BL/6J mice were resistant to more than 1,000 PFU of $R$. akari Kaplan or 1,000 $\mathrm{MLD}_{50}$ as measured in $\mathrm{C} 3 \mathrm{H} / \mathrm{HeJ}$ mice. Sex of the animals was not a factor, since C57BL/6J females were as resistant as males. There was no indication from the survey of 17 inbred strains that susceptibility to lethal infection was associated with a particular $H-2$ haplotype.

The $F_{1}$ progeny derived from the cross of inbred parents with different susceptibilities to the Kaplan strain were uniformly resistant to Kaplan challenge, regardless of sex, indicating that resistance was a dominant trait. Testing of $\mathrm{F}_{2}$ and parental backcross generations of $\mathrm{C} 3 \mathrm{H} /$ HeJ and DBA/2J hybrids yielded ratios of resistant to susceptible animals that suggested resistance was under multigeneic control. However, the ability of Kaplan strain rickettsiae to produce plaques in $\mathrm{C} 3 \mathrm{D} 2 \mathrm{~F}_{1}$ mouse embryo cell cultures indicated that resistance was not due to the inability of these rickettsiae to enter and proliferate in the cells of resistant animals. Other investigators (10) have suggested that resistance of inbred strains of mice to experimental rickettsialpox was correlated with the rickettsiacidal capacity of mouse macrophages. Our studies did not address directly the role of immunocompetent cells in resistance to infection, but the protective response elicited in $\mathrm{C} 3 \mathrm{H} / \mathrm{HeJ}$ mice by immunization with the Hartford strain indicated that stimulation of the immune system had a dramatic effect on the outcome of the rickettsiae-host interaction.

The extreme sensitivity of the $\mathrm{C} 3 \mathrm{H} / \mathrm{HeJ}$ mouse strain to lethal infection with $R$. akari Kaplan makes it particularly appealing for further studies on the pathogenesis of rickettsial infection. However, this mouse strain possesses a B-lymphocyte defect which makes it unresponsive to lipopolysaccharide stimulation (6) and evidences differences in macrophage activation for tumor cytotoxicity when compared with the resistant $\mathrm{C} 3 \mathrm{H} / \mathrm{HeN}$ strain (16). The influence of these immunological aberrations on rickettsiae-host interactions is unknown, but merits careful consideration in the interpretation of events occurring during experimental rickettsialpox infection.

\section{ACKNOWLEDGMENTS}

We thank Robert C. Bishoff and Van D. Walters for expert technical assistance and Carol J. Larson for secretarial support.

\section{LTFRATURE CITED}

1. Bradley, D. J. 1974. Genetic control of natural resistance to Leishmania donovani. Nature (London) 250:353.

2. Cheers, C., and I. F. C. McKenrie. 1978. Resistance and susceptibility of mice to bacterial infection: genetics of listeriosis. Infect. Immun. 19:755-762.

3. Darnell, M. D., H. Koprowski, and K. Lagerspetz. 1974. Genetically determined resistance to infection with group $B$ arboviruses. I. Distribution of the resistance gene among various mouse populations and characteristics of gene expression in vivo. J. Infect. Dis. 129: 240-247.

4. Eustis, E. B., and H. S. Fuller. 1952. Rickettsialpox. II. Recovery of Rickettsia akari from mites, Allodermanyssus sanguineus, from West Hartford, Conn. Proc. Soc. Exp. Biol. Med. 80:546-549.

5. Finney, D. J. 1971. Statistical methods in biological assay, 2nd ed., p. 524-530. Charles Griffin, London.

6. Glode, L. M., I. Scher, B. Osborne, and D. L. Rosenstreich. 1976. Cellular mechanism of endotoxin unresponsiveness in C3H/HeJ mice. J. Immunol. 116:454461.

7. Groves, M. G., and J. V. Osterman. 1978. Host defenses in experimental scrub typhus: genetics of natural resistance to infection. Infect. Immun. 19:583-588.

8. Huebner, R. J., W. L. Jellison, and C. Armstrong. 1947. Rickettsialpox - a newly recognized rickettsial disease. V. Recovery of Rickettsia akari from a house mouse (Mus musculus). Public Health Rep. 62:777-780.

9. Huebner, R. J., P. Stamps, and C. Armstrong. 1946. Rickettsialpox-a newly recognized rickettsial disease. I. Isolation of the etiological agent. Public Health Rep. 61:1605-1614

10. Kokorin, I. N., E. A. Kabanova, C. D. Kyet, E. D. Miskarova, and G. E. Abrosimova. 1978. Differences in the susceptibility of mouse lines to the rickettsial pox agent. Acta Virol. 22:497-501.

11. Kyet, C. D. 1977. Differences in the interlinear sensitivity 
of mice to the causative agents of rickettsialpox. $\mathrm{Z}$. Mikrobiol. Epidemiol. Immunobiol. 54:78-81.

12. Lilly, F., E. A. Boyse, and L. J. Old. 1964. Genetic basis of susceptibility to viral leukaemogenesis. Lancet ii: 1207-1210.

13. Lopez, C. 1975. Genetics of natural resistance to herpesvirus infections in mice. Nature (London) 258:152-153.

14. Plant, J., and A. A. Glynn. 1974. Natural resistance to Salmonella infection, delayed hypersensitivity and Ir genes in different strains of mice. Nature (London) 248: 345-347.

15. Plant, J., and A. A. Glynn. 1976. Genetics of resistance to infection with Salmonella typhimurium in mice. J. Infect. Dis. 133:72-78.

16. Ruco, L. P., and M. S. Meltzer. 1978. Macrophage activation for tumor cytotoxicity: tumoricidal activity by macrophages from $\mathrm{C} 3 \mathrm{H} / \mathrm{HeJ}$ mice requires at least two activation stimuli. Cell. Immunol. 41:35-51.
17. Sammons, L. S., R. H. Kenyon, R. L. Hickman, and C. E. Pederson, Jr. 1977. Susceptibility of laboratory animals to infection by spotted fever group rickettsiae. Lab. Anim. Sci. 27:229-234.

18. Smadel, J. E., and E. B. Jackson. 1964. Rickettsial infection, p. 743-770. In E. H. Lennette and N. J. Schmidt (ed.), Diagnostic procedures for viral and rickettsial disease, 3rd ed. American Public Health Association, Inc., New York.

19. Staats, J. 1972. Standardized nomenclature for inbred strains of mice: fifth listing. Cancer Res. 32:1609-1646.

20. Wike, D. A., G. Tallent, M. G. Peacock, and R. A Ormsbee. 1972. Studies of the rickettsial plaque assay technique. Infect. Immun. 5:715-722.

21. Williams, D. M., F. C. Grumet, and J. S. Remington. 1978. Genetic control of murine resistance to Toxo. plasma gondii. Infect. Immun. 19:416-420. 